\title{
O regime jurídico das contribuições de intervenção no domínio econômico frente ao sistema tributário nacional brasileiro ${ }^{1}$
}

\author{
Thiago Conte Lofredo Tedeschi ${ }^{2}$ \\ Marlene Kempfer Bassoli ${ }^{3}$
}

\begin{abstract}
Resumo
O Estado intervem no domínio econômico seja como Estado-empresário (intervenção direta), seja no exercício de suas funções, como regulação, fiscalização, incentivo e planejamento (intervenção indireta, nos termos do Art. 174 CF)). Neste sentido, de extrema importância o estudo dos valores e regras econômico-constitucionais ( Art. $170 \mathrm{CF}$ ), para afirmar quando é que há autorização constitucional para intervir. A intervenção se justifica somente se for para atender este regime jurídico. Para custear a intervenção indireta pode a União instituir Contribuição de Intervenção sobre o Domínio Econômico-CIDE (Art. 149 CF). A constitucionalidade desta contribuição deve ser avaliada à luz do regime constitucional tributário bem como da exigência de rígido controle de destinação destes recursos para custear a atividade de intervenção, entre elas, a estrutura administrativa estatal criada para tal fim. A tredestinação deve ser fundamento para a declaração judicial de inconstitucionalidade.
\end{abstract}

Palavras-Chave: Direito Tributário; CIDE; Tributo; Intervenção; Economia.

\section{Introdução}

É sabido que, dia após dia, a evolução humana, transforma inúmeros setores da sociedade, moldando, assim, aos valores sociais emergentes. Neste sentido, desde os primórdios da convivência social, os valores, e aqui merecem destaque os valores econômicos, influem consideravelmente o processo de positivação.

O Direito positivado expõe os inúmeros contornos econômicos idealizados ao longo de toda a história, por influência de ensinamentos, como os iniciais pensamentos de Adam Smith, o Estado Social de Keynes, e até o Estado Neoliberal de Hayek.

Como fundamento nestas idéias, vem à tona a intervenção do Estado no domínio econômico para realizar os valores e regras que compõem o regime econômico constitucional, reunidos no Art. 170 da CF. Esta atuação estatal por meio dos instrumentos

Artigo produzido a partir do Trabalho de Conclusão do Curso (TCC)

Acadêmico do 5o ano do curso de Direito da Universidade Estadual de Londrina.

Professora da graduação e pós graduação da Universidade Estadual de Londrina, Puc-Londrina e UNIMAR. 
regulatório e de fiscalização, elencados no Art. 174 da CF, em setor de relevante interesse público, pode ser financiada por meio das Contribuições de Intervenção no Domínio Econômico (CIDE)

Delimita-se o estudo especificamente às CIDES, abordadas a partir de uma leitura histórica deste tributo em face das Constituições brasileiras. Na seqüência, são feitas considerações acerca das características das Contribuições de Intervenção no Domínio Econômico, para apontar as principais finalidades das intervenções econômicas. Parte-se para uma análise crítica de sua atual efetividade no Brasil, principalmente no que se refere ao conflito entre o que se arrecada e a destinação das receitas vinculadas às CIDES.

\section{As CIDES nas Constituições brasileiras}

As CIDES tiveram respaldo constitucional no direito alemão. A doutrina alemã apelida estas contribuições de tributos especiais (Sonderabgaben) diferenciando-as das demais contribuições (Beiträge), também de natureza tributária (MAIDA, 2004, p. 3).

No Brasil, tal tributo aparece pela primeira vez na Constituição de 1934, até porque, as duas Constituições Federais promulgadas anteriormente (1824 e 1891) sofreram enorme influência do liberalismo econômico, inibindo qualquer tipo de intervenção por parte do Estado na economia.

O texto Constitucional de 1934 previa a regulação de atividades econômicas por parte do Estado para intervir no setor privado, garantindo assim a justiça, as necessidades da vida nacional e a liberdade econômica. Tal Constituição nada mencionava a respeito das CIDES como instrumento de intervenção, traçando apenas, no Art. 124, a possibilidade de cobrança de Contribuições de Melhoria quando da valorização imobiliária causada por um agir estatal (obras públicas).

Já em 1937, quando da nova Constituição, verifica-se a utilização da expressão Intervenção do Estado no Domínio Econômico no Art. 135. Assim como na Constituição de 1946, um tributo interventivo ainda não havia sido determinado constitucionalmente.

Em 1967, sob reflexo do golpe de Estado recém ocorrido e com base nos princípios de valorização do labor humano, da função social da propriedade e da livre iniciativa, entre inúmeros outros presentes no Art. 157 do referido Texto Constitucional, o Estado passa a intervir no domínio econômico, por meio da União Federal. 
A Constituição de 1988, mantém a possibilidade de criação de CIDES para que seja possível a preservação dos princípios do Art. 170 bem como dos objetivos presentes no Art. 3ㅇ do mesmo Texto Constitucional.

\section{As influência ideológicas para a definição do regime jurídico econômico constitucional}

Embora não seja exclusivamente a Escola Econômica Neoliberal a exercer influência no que se refere às atividades que ocorrem no domínio econômico no Brasil, considera-se decisiva.

A liberdade total que dispunha a iniciativa privada no auge do movimento liberal acabou por gerar problemas econômicos, entre eles, a concentração de renda que abriu caminho para uma forte onda de exclusão social. Por essa razão, o Estado se viu forçado a alterar seu papel no cenário econômico-social.

O liberalismo clássico passa por alterações aceitando a intervenção estatal em setores estratégicos como os que exigem infraestrutura para viabilizar as atividades econômicas. São as forças do Neoliberalismo. No entanto, é por influência do modelo social de estado, que a intervenção se amplia não somente para possibilitar uma melhor distribuição de renda, um maior equilíbrio econômico, mas, especialmente para a viabilização de direitos fundamentais.

Nesta seara, o Estado brasileiro mantém seu papel de garantir segurança à desenvoltura e estabilidade das atividades econômicas particulares. Deve, também, viabilizar políticas públicas que garantam outros direitos fundamentais além dos direitos individuais. Cite-se como exemplo aqueles que estão enumerados na Constituição Federal no capítulo que trata dos princípios gerais da atividade econômica. Para cumprir esta atribuição os governos têm autorização constitucional para intervir no domínio econômico por meio da produção de normas, de ações fiscalizatórias, ações afirmativas de incentivo e de planejamento.

É possível indicar que no regime econômico constitucional brasileiro tem-se presente influências das idéias: do liberalismo (livre iniciativa, livre concorrência, propriedade privada); do neoliberalismo (intervenção estatal no domínio econômico para viabilizar atividades de interesse econômico); e dos movimentos sociais, que acabaram 
influenciando, fortemente, os denominados estados sociais (direito fundamentais sociais e transindividuais, propriedade privada com função social).

\section{Formas de intervenção do Estado no domínio econômico}

A intervenção estatal no cenário econômico, constitucionalmente admitida, é possível por meio de duas formas: a intervenção estatal direta e a indireta.

Denomina-se, intervenção direta quando o Estado participa em igualdade de condições com a iniciativa privada (Art. 173, CF), ou seja, atua como empresário, criando empresas públicas e atuando na economia mediante autorização legal e diante dos motivos de segurança nacional e relevante interesse coletivo. Ao atuar de forma empresarial participa do domínio econômico e às regras de mercado estará sujeito, sem privilégios sob pena de promover concorrências desleais.

Com base na análise do Art. 173 da Constituição Federal, verificam-se os requisitos para esta atuação: necessidade de autorização legislativa que não precisará ter o caráter nacional, uma vez que os membros da federação poderão, também, atuar neste domínio. Quando o motivo for segurança nacional, interpreta-se que somente a União poderá criar empresa para tal, por esta uma das suas atribuições previstas na Constituição Federal.

Já na intervenção indireta o Estado deixa de agir como empresário para agir nas atribuições de agente normativo e regulador, fiscalizando, estimulando e planejando determinado setor da economia (Art. 174, CF).

O Estado impõe regras e condições por meio da denominada "função de polícia", para a realização de determinada atividade econômica, de forma a manter o equilíbrio econômico, preservar a livre iniciativa e concorrência, e ainda proteger o consumidor de eventuais danos causados pela conduta das empresas atuantes no mercado (SALOMÃO FILHO, 2001, p. 30-35).

No que tange aos incentivos para determinado setor da economia, objetivando o aumento das externalidades positivas, a intervenção estatal se dá pela "função de fomento". Estes estímulos podem ocorrer de várias formas, como por meio de benefícios fiscais, empréstimos e subsídios, em acordo com o Art. 174 da Constituição. 
O planejamento é uma forma de intervenção do estatal na economia com base numa organização das atividades econômicas, preparando a economia para investimentos futuros.

\section{0 custeio da intervenção estatal indireta: contribuição de intervenção no domínio econômico}

Há previsão constitucional para a criação de contribuições visando única e exclusivamente ao custeio das intervenções estatais indiretas no âmbito econômico. São estas as Contribuições de Intervenção no Domínio Econômico (CIDEs), nos termos do artigo 149 do Texto Constitucional brasileiro.

Entre as CIDEs instituídas no Brasil, destaca-se aquelas intervenções em setores de atividade econômica como o canavieiro, o de exportação de café, o de comércio e da produção de borracha e atualmente a de maior destaque denominada de CIDE combustível.

A finalidade das CIDES é custear a intervenção no domínio econômico, a fim de moldar as atividades econômicas ao regime jurídico-econômico constitucional. Nas palavras de Hugo de Brito Machado (2006, p. 422):

\footnotetext{
A finalidade da intervenção no domínio econômico caracteriza essa espécie de contribuição social como tributo de função nitidamente extrafiscal. Assim, um tributo cuja finalidade predominante seja a arrecadação de recursos financeiros jamais será uma contribuição social de intervenção no domínio econômico.

A finalidade interventiva dessas contribuições, como característica essencial dessa espécie tributária, deve manifestar-se de duas formas, a saber: (a) na função da própria contribuição, que há de ser um instrumento da intervenção estatal no domínio econômico, e ainda, (b) na destinação dos recursos com a mesma arrecadados, que só podem ser aplicados no financiamento da intervenção que justificou sua instituição.
}

A intervenção consiste em atividade excepcional, e por isto mesmo, temporária, tendente a corrigir distorções em setores determinados e estruturais para o desenvolvimento das atividades econômicas. O descompasso em setores econômicos pode ocorrer de duas formas: na hipótese de a atividade econômica desrespeitar os princípios constitucionais, por meio de geração de externalidades negativas, ou quando a atividade econômica não está sendo desenvolvida em sua plenitude, deixando de gerar externalidades 
positivas. Assim, a intervenção se justifica por meio de regulação, fiscalização, incentivo e planejamento (Art. $174 \mathrm{CF}$ ).

Em síntese, esclarecem Hamilton Dias e Tércio Sampaio Ferraz Júnior (2002, p. 71):

[...] a instituição de contribuição de intervenção é possível quando haja (i) efetiva intervenção do Estado no domínio econômico, nos limites das possibilidades constitucionalmente previstas para tanto, (ii) em atividade originariamente reservada ao setor privado ou que tenha a este sido transferida por autorização, concessão ou permissão, (iii) e que cause um gasto excepcional do Estado ou benefício especial a determinado grupo de indivíduos, componentes do setor objeto da intervenção efetuada.

Para o doutrinador Luciano Amaro (2003, p. 54), "trata-se de contribuições que, à vista do próprio Art. 149 , só podem destinar-se a instrumentar a atuação da União no domínio econômico, financiando os custos e encargos pertinentes".

Bellan (2002, p. 23) expõe sobre as hipóteses de intervenção no domínio econômico:

A intervenção poderá, então, consubstanciar-se na própria exigência da CIDE (nos moldes da extrafiscalidade exercida por meio do II, IE, IPI e IOF) ou em alguma atividade material a ser realizada pela União Federal com emprego dos recursos arrecadados.

A CIDE possui caráter eminentemente transitório, devendo cessar tão logo a intervenção em determinado setor conseguir restabelecer-se atendendo aos valores e regras que estão indicadas na Constituição.

A destinação das receitas auferidas com as contribuições necessita ser destinada às suas finalidades legais. A destinação do produto da arrecadação é elemento essencial para a sua validade jurídica, o que justifica a investigação de sua real aplicação dentro do ordenamento jurídico (VINHA, 2006, p. 142).

A CIDE possibilita financiar a estrutura estatal para viabilizar a intervenção do Estado nas atividades econômicas. A destinação de seus recursos deve ser para determinado órgão responsável pela realização da intervenção ou para um fundo específico que promova o financiamento das atividades.

Para Derzi (1989, p. 228-229), a CIDE deve respeitar os seguintes parâmetros: 
Devem ter uma configuração especial e não difusa. De modo que é exatamente a leitura desses princípios que vai nos dar o perfil dessa intervenção do Estado no domínio econômico. Em primeiro lugar, a intervenção há de ser feita por lei; em segundo lugar, o setor da economia deve estar sendo desenvolvido pela iniciativa privada para que possa configurar um ato de intervenção no domínio econômico. $E$ as finalidades são exatamente aqueles princípios arrolados no Capítulo da Ordem Econômica entre outros, lembremos, assegurar a livre concorrência, reprimir o abuso do poder econômico, reprimir o aumento arbitrário dos lucros, assegurar ou proteger a empresa brasileira, especialmente, diz a Constituição; a empresa brasileira de capital nacional de pequeno porte.

Feita a arrecadação é indispensável que a receita seja utilizada para custear a atividade interventiva e que em última análise reverterá em benefício ao setor que sofreu a intervenção. Para isso, indica-se a criação de um fundo, onde serão depositados os recursos que custearão a intervenção.

Urge ressaltar que a identificação do grupo receptor do benefício é indispensável à caracterização de qualquer contribuição especial, salvo no que tange àquelas da Seguridade Social, de amplitude suficiente para abranger toda a sociedade (Art. 194 do texto Constitucional).

Conforme interpretação de Hugo de Brito Machado (2006, p. 422), a lei que institui uma Contribuição de Intervenção no Domínio Econômico deve definir: sua hipótese de incidência no estreito campo da atividade econômica na qual vai atuar como instrumento de intervenção estatal; bem como, indicar expressamente a destinação dos recursos a serem arrecadados, que evidentemente não pode ultrapassar o âmbito da atividade interventiva.

Nesta seara, prescreve Tácio Lacerda Gama (2003, p. 266):

É justamente a destinação específica que autoriza a sua criação. Com efeito, se o destino daquilo que se arrecada com esses tributos não for a intervenção especifica que ensejou sua criação, o tributo terá outra natureza, diversa das contribuições. 0 regime jurídico aplicável, por isso, também será diverso. Assim, será possível falar em imposto ou em qualquer outra espécie de exação, exceto em contribuições interventivas.

Já Luciano da Silva Amaro (1991, p. 284-285), assim prescreve:

[...] há situações em que a destinação do tributo é posta pela Constituição como aspecto integrante do regime jurídico da figura tributária, na medida em que se apresenta como condição, pressuposto ou aspecto do exercício legítimo (isto é, constitucional) da competência tributária. 


\section{Tredestinação das CIDES}

É importante para a caracterização das Contribuições de Intervenção no Domínio Econômico que a receita seja efetivamente direcionada ao cumprimento da finalidade interventiva, de tal maneira que somente assim estar-se-ia justificando a existência do tributo.

Questionar a tese de que tal requisito seria fundamental à validade das CIDES seria agir com complacência no que se refere ao desvio de finalidades no Direito Tributário. Ora, a utilização da receita em prol de atividade econômica certa e determinada é justamente o diferencial das contribuições aqui estudadas, sofrendo abalo suficiente para desconstituir a existência das CIDES caso se aceitasse como normal qualquer desvio de finalidade neste tributo.

Embora ressaltada a importância de que não haja qualquer tipo de desvio de finalidade (tredestinação) na aplicação dos recursos advindos desta contribuição o que se constata atualmente no Brasil é uma total ineficácia deste tipo de tributação, causada justamente pelo uso impróprio da receita fruto da arrecadação das CIDES. O desvio para setores diversos, descaracteriza o tributo e tornando-o cada vez menos efetivo dentro de sua esfera de finalidades.

Ao se esquivar de suas finalidades originárias, o tributo deixa de cumprir com sua função social e consequentemente acaba por distanciar ainda mais a justiça fiscal, passando a servir meramente como fonte arrecadatória do Estado, trazendo por terra a razão de ser do tributo.

Ao desviar-se da finalidade originária das CIDES acaba por se agir em desacordo com a Constituição brasileira, que diferencia o instituto dos demais meios de tributar o contribuinte justamente pela utilização específica da receita arrecadada em prol de atividade de interesse exclusivo daqueles que contribuem para determinada CIDE. O desvio de finalidade tornando-a inconstitucional.

\section{Conclusão}

Os referencias dos modelos liberais, sociais e neoliberais servem de fundamento, também, para a definição do regime constitucional econômico. No Brasil há autorização para 
que os governos possam intervir no domínio econômico quer seja sob a forma empresarial (intervenção direta, nos termos do Art. 173 CF) ou sob forma de regulação, fiscalização, incentivo e planejamento (intervenção indireta, nos termos do Art. 174 CF). O fundamento ideológico desta autorização está nos referencias do estado neoliberalismo e, também, do estado social.

Ao intervir como agente econômico (Art. 174 CF) é preciso autorização legal e desde que presentes os motivos de segurança nacional e relevante interesse coletivo. Para a intervenção indireta ser legítima deve ser temporário, para setores específicos de relevante interesse econômico-social e que tenha por finalidade realizar os valores e regras que compõem o regime jurídico-econômico constitucional.

Para a intervenção indireta, por vezes, os governos precisam construir uma estrutura administrativa sendo que todos os custos da intervenção devem ser custeados pelos sujeitos submetidos à intervenção. A obtenção desta receita se dá por meio da instituição do tributo denominado de Contribuição de Intervenção no Domínio Econômico (CIDEs).

Deve ser respeitada a finalidade dos recursos obtidos por meio das Contribuições de Intervenção no Domínio Econômico, de forma a se equilibrar a arrecadação e destinação. Atualmente não há uma real preocupação governamental em evitar o desvio dos recursos das CIDES, de tal maneira que estas vêm sendo fortemente criticadas, sendo questionadas, inclusive, no que se refere à constitucionalidade. Isso ocorre em face da descaracterização do tributo causada pelos desvios de finalidade. O próprio conceito desta contribuição traz a idéia de tributo cuja arrecadação seria utilizada especificamente para gerar benefícios no respectivo setor econômico, o que deixa de acontecer a cada vez que a finalidade de determinada CIDE é desviada.

O agir do Estado deve ser efetivo no cumprimento do Art. 174 da Constituição Federal de 1988 a fim de que seja possível assegurar a todos a eficácia objetivada pelo caput do Art. 170 do mesmo texto, possibilitando desenvolvimento social e econômico.

Nessa vertente é de vital importância para a sobrevivência da CIDE que o Poder Judiciário atue de forma efetiva no controle da destinação destes recursos tributários, reprimindo qualquer tipo de desvio de finalidade. Desta forma, permitindo uma efetiva 
aplicação dos recursos públicos conforme autorização constitucional. Destaca-se que, enquanto houver desvio de finalidade, será o tributo inconstitucional.

\section{Referências}

AMARO, Luciano da Silva. Conceito e classificação dos tributos. Revista de Direito Tributário, São Paulo, v.55.

BELLAN, Daniel Vitor. Contribuições de intervenção no domínio econômico. Revista Dialética de Direito Tributário, São Paulo, n.78.

DERZI, Misabel. Contribuições. Revista de Direito Tributário, São Paulo, v. 48.

FERRAZ JÚNIOR, Tércio Sampaio; SOUZA, Hamilton Dias de. Contribuições de intervenção no domínio econômico e a federação. In: MARTINS, Ives Gandra da Silva (Coord.). Contribuições de intervenção no domínio econômico. São Paulo: RT, 2002.

GARCIA, Manuel Enriquez; VASCONCELLOS, Marco Antonio Sandoval. Fundamentos de economia. São Paulo: Saraiva, 2000.

MACHADO, Hugo de Brito. Curso de direito tributário. 27. ed. São Paulo: Malheiros, 2006.

MAIDA, Fernando. O caráter fiscal e extrafiscal da CIDE sobre as atividades na indústria de petróleo. Jus Navigandi, Teresina, v. 8, n. 181, 3 jan. 2004. Disponível em:

<http://jus2.uol.com.br/doutrina/texto.asp?id=4627>. Acesso em: 11 maio 2007

MEIRELLES, Hely Lopes. Direito administrativo brasileiro. 25. ed. São Paulo: Malheiros, 2000.

SALOMÃO FILHO, Calixto. Regulação da atividade econômica: princípios e fundamentos jurídicos. São Paulo: Malheiros, 2001.

SILVA, Américo Luis Martins da. A ordem constitucional econômica. Rio de Janeiro: Lúmen Júris, 1996.

VINHA, Thiago Degelo. A contribuição de intervenção no domínio econômico incidente sobre combustíveis e derivados. 2006. 206 f. Dissertação (Mestrado em Direito) - Universidade de Marília, Marília, 2006.

WONNACOTT, Paul; WONNACOTT, Ronald. Economia. 2. ed. São Paulo: Makron Books, 1994. 